This item was submitted to Loughborough's Research Repository by the author.

Items in Figshare are protected by copyright, with all rights reserved, unless otherwise indicated.

\title{
Defining and characterizing team resilience in elite sport
}

PLEASE CITE THE PUBLISHED VERSION

http://dx.doi.org/10.1016/j.psychsport.2013.01.004

\section{PUBLISHER}

(c) Elsevier

\section{VERSION}

AM (Accepted Manuscript)

\section{PUBLISHER STATEMENT}

This work is made available according to the conditions of the Creative Commons Attribution-NonCommercialNoDerivatives 4.0 International (CC BY-NC-ND 4.0) licence. Full details of this licence are available at: https://creativecommons.org/licenses/by-nc-nd/4.0/

\section{LICENCE}

CC BY-NC-ND 4.0

\section{REPOSITORY RECORD}

Morgan, Paul B.C., David Fletcher, and Mustafa Sarkar. 2019. "Defining and Characterizing Team Resilience in Elite Sport". figshare. https://hdl.handle.net/2134/22689. 
1

2

3

4

5

6

7

8

9

10

11

12

Defining and Characterizing Team Resilience in Elite Sport

13

14

15

16

17

18

19

20

21

22

23

24 Date of submission: September 10, 2012

25 Date of revised submission: December 3, 2012 
Abstract

2 Objectives: The objectives of this study were to develop a definition of team resilience and to

3 identify the resilient characteristics of elite sport teams.

4 Design and Method: Focus groups consisting of a total of 31 participants were conducted

5 with five elite teams from a range of sports. An interpretive thematic analysis using inductive

6 and deductive reasoning was employed to analyze the data.

$7 \quad$ Results and Conclusions: Team resilience was defined as a dynamic, psychosocial process

8 which protects a group of individuals from the potential negative effect of the stressors they

9 collectively encounter. It comprises of processes whereby team members use their individual

10 and combined resources to positively adapt when experiencing adversity. Findings revealed

11 four main resilient characteristics of elite sport teams: group structure, mastery approaches,

12 social capital, and collective efficacy. This study extends resilience research in sport

13 psychology by providing greater conceptual clarity of resilience at a team level. The

14 implications of the findings for those conducting research in this area and for those consulting

15 with elite sport teams are discussed.

16 Keywords: adversity, definition, excellence, positive adaptation, resilient

17 characteristics. 
Defining and Characterizing Team Resilience in Elite Sport Resilience is recognized as an important psychological phenomenon for understanding the positive development of people who overcome a variety of difficulties during the course of their lives (Masten \& O’Dougherty Wright, 2010). Within elite sport, teams frequently experience adversity, and being able to positively adapt to such situations represents a significant challenge for athletes and coaches. Indeed, research in sport psychology has revealed that specific stressors are encountered within elite team environments, including the quality of coach-player interactions, poor communication channels, letting teammates down, and negative aspects of organizational culture (see, e.g., Holt \& Hogg, 2002; Nicholls, Polman, Levy, Taylor, \& Cobley, 2007; Noblett \& Gifford, 2002). Although such research has identified the types of stressors present within team environments, the exploration of how a team's collective resources can be harnessed to positively adapt to adversity has been largely overlooked in the sport psychology literature. Recently, however, team resilience has emerged as an important concept in business and health psychology and researchers have begun to elucidate how groups respond favorably to adverse events (see, e.g., Bennett, Aden, Broome, Mitchell, \& Rigdon, 2010; West, Patera, \& Carsten, 2009).

Resilience has been defined as, “a dynamic process encompassing positive adaptation within the context of significant adversity” (Luthar, Cicchetti, \& Becker, 2000, p. 435). Two conditions of resilience are understood to be inherent within this definition: firstly, that there is exposure to significant adversity (or risk) and secondly that positive adaptation (or competence) occurs (Masten, 2001). Early resilience research unearthed various factors that protect individuals from the potential negative effects of stressors (see, e.g., Garmezy, 1991). These characteristics, which are often referred to as protective factors in the resilience literature, have been identified at individual, family, and community levels and include 
1 qualities such as adaptability, a positive family climate, and positive attachment relationships

2 (Werner \& Smith, 1992). Since the early 1990s, the focus of resilience research has shifted

3 away from identifying resilient qualities towards conceiving resilience as a dynamic process

4 (Luthar et al., 2000; Masten, 2001; Richardson, 2002). When conceived as a dynamic

5 process, it has been suggested that resilience is a capacity that develops over time in the

6 context of person-environment interactions (Egeland, Carlson, \& Sroufe, 1993). That is, the

7 extent to which an individual reacts positively to adversity depends on the nature of the

8 demands encountered and how he or she adapts to the circumstances.

Despite advances in the conceptualization of resilience in general psychology (see, for a review, Fletcher \& Sarkar, in press), the importance of this construct has only recently been recognized in sport psychology research. In 2004, Holt and Dunn employed a grounded theory approach to identify and examine psychosocial competencies among elite male adolescent soccer players. Interestingly, resilience emerged as one of the four major themes regarded as central to an individual's soccer success. Specifically, being able to thrive under pressure and respond positively to setbacks were considered to be important features of resilience. In the first study to specifically investigate resilience in sport, Galli and Vealey (2008) explored individual athlete’s perceptions of resilience in relation to the adversities they had encountered. The major themes that emerged from this qualitative study were: breadth and duration of the resilience process, agitation (e.g., coping strategies), personal resources (e.g., determination), and sociocultural influences (e.g., social support). Using quantitative analyses, Gucciardi, Jackson, Coulter and Mallett (2011) examined individual resilient qualities in a sport context. Examples of such qualities were adaptability, staying focused under pressure, and handling unpleasant feelings. Results provided partial support for the revised 10-item Connor-Davidson Resilience Scale (Campbell-Sills \& Stein, 2007; Connor \& Davidson, 2003) across samples of adolescent and adult Australian cricketers. 
1 Most recently, Fletcher and Sarkar (2012) interviewed twelve Olympic champions to explore

2 and explain the relationship between psychological resilience and optimal sport performance.

3 They found that numerous psychological factors (relating to a positive personality,

4 motivation, confidence, focus, and perceived social support) protect the world's best athletes

5 from the potential negative effect of stressors by influencing their challenge appraisal and

6 meta-cognitions. These constructive cognitive reactions promoted facilitative responses that

7 appeared to be firmly embedded in taking personal responsibility for one’s thoughts, feelings,

8 and actions. In turn, positive responses led to the realization of optimal sport performance.

9 Although this body of work provides an insight into resilience in sport, the focus to date has

10 specifically been on individual resilience and, therefore, questions remain about the nature of

11 team resilience in sport.

Recent resilience research in community psychology and organizational behavior has

shifted away from individuals toward the study of groups and teams (Brodsky et al., 2011;

Norris, Stevens, Pfefferbaum, Wyche, \& Pfefferbaum, 2008). Resilience at the group level

has been characterized by psychosocial factors such as caring relationships and effective

teamwork generated through trust, cohesion, creativity, collective efficacy, and relational reserves (Blatt, 2009; Gittell, Cameron, Lim, \& Rivas, 2006; Lengnick-Hall, Beck, \& Lengnick-Hall, 2001; Norris et al., 2008). Furthermore, groups that retain a broader perspective when faced with stressors are able to positively adapt to demanding situations by embracing challenging experiences and adopting a learning orientation (Bennett et al., 2010; Sutcliffe \& Vogus, 2003; West et al., 2009). Reinforcing the need for group level resilience research, Bennett et al. (2010) remarked that, “resilience may be viewed as much a social factor existing in teams as an individual trait” (p. 225). This statement suggests that team members do not exist in isolation and that they may have the capacity to adapt positively to their environment through facilitative collective interactions. Most recently, Brodsky et al. 
1 (2011) asserted that, “... a focus on the individual is not enough” (p. 233). Specifically, they

2 described a number of resilience processes operating at the organizational level including:

3 creating a culture that strengthens a sense of community, reframing of organizational

4 stressors, taking action based on the organization's mission and ideology, developing shared

5 value systems, and enhancing adaptability through flexible team structures (see also Fletcher

6 \& Wagstaff, 2009; Wagstaff, Fletcher, \& Hanton, 2012). These processes support Chan’s

7 (1998) contention that constructs in the same content domain (e.g., resilience) are manifested

8 in different ways at different levels of analysis (e.g., individual or team). Based on this

9 notion, we propose that the development of a robust conceptual scaffold for team level

10 resilience research will provide greater clarity about how resilience is defined and

11 characterized in teams. Indeed, team resilience has a critical and distinctive role to play for

12 those functioning in groups, as suggested by West et al. (2009):

Team resilience may prove to be an important positive team level capacity that aids in the repair and rebound of teams when facing potentially stressful situations. Teams which display the ability to either thrive under high liability situations, improvise and adapt to significant change or stress, or simply recover from a negative experience are less likely to experience the potentially damaging effects of threatening situations. (p. 254)

Although sport psychology research is beginning to shed light on the resiliencerelated characteristics and processes at the individual level, the nature of resilience at the team level requires specific examination in the sport context. Team level resilience research in elite sport may not only provide important knowledge about how resilient teams manage the unique stressors they collectively encounter but also about their ability to sustain high performance despite the ever-changing, complex environment of elite sport. Therefore, the purpose of this study is to explore team resilience in elite sport. Specifically, the objectives 
1 are to develop a definition of team resilience and to identify the resilient characteristics of

2 elite sport teams. It is hoped that this study will provide practitioners with a framework to

3 profile resilient characteristics of teams when encountering adversity. In turn, this could

4 facilitate the design of team-based resilience interventions for athletes and coaches operating

5 in elite sport.

6

\section{Method}

\section{$7 \quad$ Research Design}

8

In accordance with exploratory studies that seek to collect rich data to portray complex human experiences (cf. Silverman, 2006), a qualitative design was adopted in this study. Moreover, given that qualitative research emphasizes the exploration of social and interactive explanations arising from human behavior (King \& Horrocks, 2010), a qualitative investigation was deemed to be particularly appropriate for the exploration of a group level concept, such as team resilience in this case (cf. Ungar, 2003). Focus groups were adopted to elicit a collective conversation about team resilience. Indeed, Liamputtong (2011) has suggested that, "focus group interviews allow group dynamics and help the researcher capture shared ... experiences, accessing elements that other methods may not be able to reach” (p. 4).

\section{Participants}

The sample in this study included a total of 31 participants (17 female, 14 male) who ranged in age from 18 to 36 years $(M=25.7, S D=5.2)$. The participants had been competing in their respective teams for between 1 and 12 years $(M=4.55, S D=3.28)$. Participants represented the following sports: rowing (six female participants), field hockey (five female participants), soccer (six male participants), handball (six female participants), and futsal (eight male participants). The rowing team members had won eight Olympic medals and 10 world titles, and the field hockey team members were ranked in the top five sides in the world 
1 with three world championship medals. The soccer team members competed professionally in

2 the English Championship division, the handball team members participated in Olympic and

3 European competition, and the futsal team members competed internationally for their

4 respective country.

5 Procedure

6

Following institutional ethical approval, the Performance Directors of each team were

7 contacted by telephone or email and the purpose and requirements of the investigation were

8 communicated. Homogeneous focus groups (i.e., groups comprising of members from the

9 same team) were established to promote interaction due to their familiarity with each other as

10 team members (Morgan, 1997; Stewart, Shamdasani, \& Rook, 2007), and to enable the

11 discussion of resilience within their own teams. In terms of the quantity of groups, Krueger and Casey (2009) suggested that typically three to four groups is appropriate when conducting applied research. In the present study, five focus groups of elite team members were completed after which saturation was deemed to have occurred. Regarding group size, focus groups of five to eight participants were used, based on Krueger and Casey’s (2009) guidelines, to promote effective interaction and exchange of views. Focus group dates were agreed at a convenient time for participants and briefing information was sent two weeks in advance by email. Venues were identified at team training centers to provide an appropriate, comfortable, and familiar setting for participants (Stewart \& Shamdasani, 1990; Liamputtong, 2011). Immediately prior to each focus group, the first author completed a record of participants' demographic details, learnt their first names, and engaged informally with them to build rapport (Morgan, 1997).

Interview Guide

Due to the exploratory nature of the study, a semi-structured interview guide was designed to facilitate a flexible interview format (Liamputtong, 2011; Stewart et al., 2007). 
1 This approach was based on Kitzinger's (1994) suggestion that group interviews should

2 promote participant engagement with each other so that they are encouraged to "verbally

3 formulate their ideas and draw out the cognitive structures which previously have been

4 unarticulated” (p. 106). The interview guide comprised five sections. Section 1 informed the

5 participants about the purpose of the interview and focused their attention on the topic under

6 consideration. Specifically, a general overview of the concept of resilience was provided and

7 the participants were told that the aim of the research was to explore what team resilience

8 meant to them in the context of elite sport. To encourage discussion about team resilience,

9 Section 2 encouraged the participants to discuss the challenges, stressors, and adversities their

10 team had faced (e.g., “Can you tell me about an adversity your team has experienced?”). In

11 Section 3, participants were asked to generate a list of characteristics associated with team resilience (e.g., “From your experiences, what are the characteristics of a resilient team?”). In Section 4, drawing on and developing the previous discussion, participants were asked to construct a definition of team resilience (e.g., "From your experiences, and bearing in mind all that we have discussed so far, how would you define team resilience?”). Section 5 used summarizing statements to provide opportunities for participants to add comments and reflect on the efficacy of the interview (Roulston, 2010b). Importantly, although the interview guide was semi-structured, the flexible format of the interview ensured that participants could pursue the discussion of their team resilience in the direction that they deemed appropriate.

Various focus group techniques were employed to allow group interactions and the creation of a "synergistic effect” (Stewart \& Shamdasani, 1990, p. 16). For example, team members were encouraged to speak to each other rather than addressing the moderator, were told that their views were valued and that there were no right or wrong answers, and were allowed to

24 focus the conversation on topics which were meaningful and important to the group.

\section{Data Analysis}


The focus groups ranged in duration from 63 to 88 minutes $(M=73.4, S D=12.5)$ and

2 were transcribed verbatim yielding 280 pages of single spaced text. Transcripts were then

3 imported into QSR NVivo Version 9 (2010). To identify the characteristics of team

4 resilience, an inductive thematic analysis was conducted. Thematic analysis is a qualitative

5 technique which unearths rich and complex accounts of data allowing for social and

6 psychological interpretations of data (Guest, MacQueen, \& Namey, 2012). In line with

7 thematic analysis procedures (Braun \& Clarke, 2006), initial emphasis was placed on reading

8 and re-reading transcripts, highlighting relevant material, and making annotations.

9 Preliminary codes (e.g., words or phrases used by participants, labels relating to the research question) representing a characteristic were then inductively identified. These raw-data responses were then clustered into lower-order sub-themes before categorizing them into higher-order themes. The higher-order themes were then clustered into general dimensions to present a more meaningful and coherent picture of the participants’ views. To establish a definition of team resilience, raw data responses and associated comments from the focus groups were clustered into sub-themes. Following this, the research team collectively reviewed the definition through a series of meetings and refined the definition, using inductive and deductive reasoning, until consensus was reached.

\section{Methodological Quality and Rigor}

Although some scholars have opposed the development of unvarying universal standards for qualitative research (cf. Sparkes \& Smith, 2009), it is important to assess the quality of a study using evaluative criteria most appropriate for the research question and emergent data (Roulston, 2010a). Judging the quality of the findings was realized in this study through adopting four main procedures. Firstly, purposive sampling was used to ensure that the experiences of the most appropriate persons for the research question being addressed 
1 current team members competing at professional, international and/or Olympic level who had

2 experience of team resilience during their sporting career. To illustrate, one focus group had

3 lost their central funding contract resulting in disjointed time together, low team morale, and

4 having to find employment. Despite this, the group had identified new ways of organizing

5 training, maintaining positive team relations, and increasing attendance at training camps.

6 Secondly, methodological rigor was enhanced through conducting two pilot focus groups

7 with members of semi-professional teams (football and rugby) to assess the structure and

8 language of each interview question, and to give the first author experience in managing an

9 interview with a group. Based on these interviews, the number of questions was reduced

10 where overlap was considered to interrupt the flow of the interview. Thirdly, the first author

11 gave consideration to the consistency in the way that focus groups were conducted

12 (Liamputtong, 2011) and used audit trails (Roulston, 2010b) by creating memos and a journal

13 to produce a reflective commentary of how the themes were developed (cf. Tracy, 2010).

14 Fourthly, quality checks were used to enable the researchers to think critically about the

15 thematic structure being developed. Specifically, a combination of code-defining and code-

16 confirming approaches was employed whereby transcripts and codes were given to an

17 independent coder for critical scrutiny and discussion (King \& Horrocks, 2010). This process served to provide the researchers with a "critical friend” to help encourage reflexivity and alternative explanations and interpretations of the data (cf. Stewart, Smith, \& Sparkes, 2011).

\section{Results}

The results, representing the participants' collated responses, present the definition and the resilient characteristics of elite sport teams. The findings are reported using a combination of direct quotations and hierarchical trees to portray the complexity and scope of the issues being investigated (cf. Culver, Gilbert, \& Sparkes, 2012) with a view to furthering readers' understanding of team resilience in elite sport. 


\section{Definition of Team Resilience}

Based on the focus group discussions, team resilience is defined as a dynamic,

3 psychosocial process which protects a group of individuals from the potential negative effect

4 of stressors they collectively encounter. It comprises of processes whereby team members use

5 their individual and collective resources to positively adapt when experiencing adversity.

6

7

Team resilience was described as a dynamic phenomenon since it was regarded as, for example, being "dependent upon what time of season it is" or whether there was "an injury in the team”. The majority of participants also described how team resilience arose from a variety of social interactions with others. To illustrate, during challenging times, the “support” or “friendship” aspect was influenced by “everybody along the chain” and dependent on "what kind of leadership there is". Most participants emphasized how resilience was typically a changing process due to the "ups and downs" of "riding the roller coaster of sport”. All of these elements were captured within the definition as "a dynamic, psychosocial process”. The following quote by a World Champion female rower highlights the dynamic nature of team resilience that can potentially fluctuate when team disruption occurs: This [disruption] can occur when somebody new comes into the wider group ... we have been through adversity together and you get to know how people react and you know that with every single person in this room, that if the **** hits the fan, they will fight with everything that they’ve got but with a new person you don’t know if they are going to crumble.

The generated definition also included the term "protects a group of individuals". This was captured by quotes describing team resilience as akin to "having a barrier round you", "having a thick skin", and by "being able to filter out" stressors. Furthermore, all of the participants emphasized that team resilience involved a shared experience of stressors and this was revealed through comments such as "we have been through so many setbacks 
1 together" and "we have been through almost every challenging situation possible at some

2 point". This aspect was captured within the definition as "they collectively encounter". The

3 final part of the generated definition of team resilience describes how "team members use

4 their individual and collective resources to positively adapt when experiencing adversity”.

5 The majority of participants described how they individually used their "self-awareness" and

6 "took personal responsibility for their actions" in potentially stressful situations. Some of the

7 participants also described how they collectively employed group resources when

8 experiencing adversity, for example, by striving to produce "a combined effort” and by

9 adopting a group mindset where "we've taken the challenge upon us, learnt things from it

10 [adversity] and improved”. Moreover, all of the participants emphasized the collective nature

11 of team resilience with comments such as, “there's . . . an unwritten rule amongst us all”. An international futsal player illustrated the importance of using collective resources during setbacks, such as agreeing to work for each other:

When there's other people at stake, you feel more strongly. . . you say to yourself, 'I'm going to do something about the situation' ... You can't not be bothered when you've got twelve other members ... you have to respond to these challenges because there’s so much at stake.

\section{Resilient Characteristics of Elite Sport Teams}

The interview data yielded 44 lower-order themes which were abstracted into 12 highorder themes. The higher-order themes were categorized into four general dimensions to represent the resilient characteristics of elite sport teams: group structure, mastery approaches, social capital, and collective efficacy (see Figures 1 to 4). A frequency analysis is provided in each figure to illustrate the number of teams mentioning each theme.

Group structure. Group structure refers to the conventions that shape group norms and roles, and involves both psychosocial and physical aspects. Group structure consisted of 
1 three higher-order themes: formal structure, group norms and values, and communication

2 channels (see Figure 1). The majority of participants suggested that formal structures

3 characterized resilient teams by mobilizing groups with the necessary people and resources to

4 adapt to stressors. For example, having a centralized team base provided “massive gains”,

5 and "strengthened group relationships" as highlighted by an elite field hockey player: "Since

6 we have become central, you know people a lot more than before and it's like everyone's

7 your mate, [and when facing difficulties] you want to do it for them and for the team”. Within

8 the formal structure higher-order theme, shared leadership roles were also identified as a

9 resilient characteristic. To illustrate, some of the participants recognized that a core set of

10 leaders were typically present during challenging situations as described by an international

11 level professional footballer:

You need a few types of leaders within the team, a captain type that is going to talk to everyone [and] help people if they've got problems or issues and then there's the leaders who lead by example by what they do on the pitch and training hard every day. [When the team encounters issues] one person can't change anything and it depends on the other players because my experience of resilient teams is that you have six or more players who could easily have done the captaincy job but it is more important that when someone is picked to do it, the rest is ready to work with him. Group norms and values denoted the informal and implicit aspects of a resilient team.

All of the athletes stated that resilient teams developed and reflected on their shared vision to provide a sense of purpose which was particularly important to turn to when facing difficult times. The following quote by an elite hockey player illustrates the importance resilient teams place on being able to challenge each other against the agreed behavioral principles of the group when reacting to pressure: 
not behaving in a manner that meets that vision . . . then that is something concrete. When times are tough, you can say to them, 'do you think that behavior is in line with that [vision]?' Whereas in the past, because we've not had that [vision], you've not been able to question anybody [during setbacks] because . . . as players we hadn't bought into the behaviors we needed to get there.

The third higher-order theme, namely communication channels, signified the various types of communication processes that resilient teams employed when encountering stressors.

The following quote by an international field hockey player illustrates how most team members would spur each other on in a match context by using frequent communication: Communication is a big thing. We talk quite a lot about our group taking it [failure] by the scruff of the neck. If you see someone trying but maybe not executing as they should, you're just like, 'come on mate, just pick yourself up a bit'. Also, throughout the group we use some buzz words which are really important during difficult moments like if we've gone one nil down we say 'the next 5 minutes is key’; it just spreads communication throughout the team and everyone knows that it just switches into their brain [and we say things like], 'right I really need to focus on what I am doing now to make sure that next time I get the ball, I am going to do it correctly’. I think it just spreads the message around us all.

Mastery approaches. Mastery approaches refer to shared attitudes and behaviors that promote an emphasis on team improvement. This characteristic consisted of three higherorder themes: learning orientation, effective behavioral responses, and managing change (see Figure 2). The higher-order theme of learning orientation was captured with reflections such as "how are we going to learn from this and turn it into a positive"? Resilient teams focused on personal development and were able to "filter out" irrelevant cues and "isolate what's important”. The quote below from an international-level footballer illustrates how a 
1 professional team learnt to reset their focus to alleviate pressure:

We have structured, detailed team briefings, match plans and tactics and they're quite precise and you really have to think about it all the time; you just keep task focused and you get back on track quicker following setbacks ... never mind if you go one goal down, you should start again ... it’s almost getting back to where you were at the start of the game [and asking yourself] 'what's my job in this team unit, what have I got to do'?

The higher-order theme of effective behavioral responses describes how resilient teams exhibited a range of positive actions to overcome stressors thereby increasing the likelihood of team progression. To illustrate, there was a strong consensus amongst the participants that thorough preparation would make a difference when encountering difficult match situations, as the following quote by an international field hockey player demonstrates: In quite a lot of our games, we'd gone one nil down ... And then we came back because ... . we knew that we'd done so much groundwork beforehand, [and we knew] that we would last the 70 minutes and that it was a case of keep going and keep doing what we're doing, knowing that they were going to die before we died. We all remembered the pain of doing all the training and we just knew that whatever, 70 minutes, 80 minutes, 90 minutes, we could last forever and that was a real difference. We just knew that we could keep grinding away despite the difficulties. The higher-order theme of managing change portrays how resilient teams were able to anticipate and adjust to stressors by "preparing yourselves to overcome any situation”. For example, a silver medalist Olympic rower mentioned how the team's accumulation of experience in challenging situations enabled them to develop a collective approach to managing changing circumstances: Because we've been through so many setbacks ... it's such a natural response 
whereas other teams who haven't necessarily been through all these setbacks might panic and it's like everything stops, whereas for us it’s like 'OK, plan B, plan C'. Social capital. Social capital refers to the existence of high quality interactions and caring relationships within groups. This characteristic consisted of three higher-order themes: group identity, perceived social support, and prosocial interactions (see Figure 3). Within the theme of group identity, the majority of the athletes described how resilient teams developed emotional bonds between teammates where “you don’t want to let the team down”, "you owe it to them" and "you would throw your life down for them". The importance of having a deep emotional bond and closeness between team members during difficult times is signified below by a double Olympic silver medalist rower:

When a crew's going well, clearly it’s got momentum and everyone is happy because the team's going well. But when things start to go badly, everyone's down, the coaches are down and everyone's on quite a low. That's when you need friendship to lift you back out of that trough and that's absolutely crucial, for at the bottom of that curve ... you know you're all there because you want to win but there's another bond there which can help you through the dark times.

The higher-order theme of perceived social support illustrates the subjective feeling that teammates would provide assistance if needed. A range of supportive processes were identified by the majority of the participants as characterizing resilient teams, namely emotional, tangible, esteem, and informational support. For example, with regards to esteem support, athletes described the importance of "building each other up", "geeing them up" and knowing support was there "from the person next to you" when facing hardship. The following quote by an international futsal player shows how the majority of the group members recognized the potentially positive influence of encouraging teammates at a time of need: 
[When tough things happen] you need to . . . support your teammates at a time when they might not be feeling it. You need to make sure they know that no matter what happens, you support them and if they’ve made a mistake, you know they’ve made a mistake trying to do the right things.

The third higher-order theme of social capital illustrated how resilient teams consisted of members that engaged in selfless exchanges during challenging situations. A world championship bronze medalist described how endeavoring to benefit the team, rather than focusing on oneself, was important for the team's resilience in a game situation:

[In those pressurized situations] it's almost like putting yourself up there to be the one that is going to fail because if you don't try, you can't fail. So being bold is saying 'give me the ball because I am going to do the right thing for my team'.

Collective efficacy. Collective efficacy refers to a group's shared beliefs in its ability to perform a task. This characteristic consisted of three higher-order themes: past mastery experiences, group cohesion, and social persuasion (see Figure 4). Within the past mastery experiences higher-order theme, most of the participants indicated that following success teams "grew in confidence" leading to a collective belief that "success is becoming something that you expect”. Interestingly, resilient teams not only gained confidence from achieving success but they also identified that the experience of adversity acted as an important source of collective efficacy. The following quote by a world champion rower illustrates how being able to draw on the experience of negative events strengthened the belief of the team:

I think that it's a little bit like, say you were rowing a boat and you had never fallen in. You have this whole, 'Oh my god, one day I am going to fall in and it's going to be horrific and I don't know how I will cope'. Whereas once you have fallen in, it's like 'actually, I survived [and] it wasn't that bad' and I think that if nothing [ever] 
went wrong you'd be really panicking. Whereas we are so used to it, and over the years, we have gone through almost every situation at some point ... and you just think, 'if we have dealt with all of that, we can deal with anything' and I think we are so much stronger for having all our ups and downs. You don’t want to wish anything on anyone but generally the athletes who have been through these experiences are so much better for it.

The theme of group cohesion was likened to being prepared to "fight for each other".

An elite field hockey player illustrated how she gained belief through knowing her teammates will show a fighting spirit in a difficult match context:

With fighting spirit ... they're [team members are] still going for it, they're still running, they're still passing it, the speed of the game is still the same and if they don’t have it [fighting spirit] it weakens the team. You can see it on the pitch, you can see when people have got it [fighting spirit], when they're absolutely dying [and] yet they're still running and pressuring the ball [for the team].

The higher-order theme of social persuasion revealed how a team's confidence was positively affected by the expressions and behaviors of group members when facing team stressors. Resilient teams, for example, gained strength through others' feedback after disappointments and this was reflected in quotes such as, "when things were going badly, the way he put it across to us made us believe” and “that obviously translates to us”. An elite handball participant described how seeing others exhibit a positive team attitude influenced the group in a positive manner:

It's a collective thing isn't it? . . . [when you're on the back foot and] you see your teammate chasing after the ball, chasing to put pressure on, that spreads . . . and the next person [thinks], 'I am definitely going to win this ball'. It's not just about them shouting, it is technical, you see them doing something well, you see them doing 
something right ... [and] that spreads.

\section{Discussion}

The objectives of this study were to develop a definition of team resilience and to identify the resilient characteristics of elite sport teams. The definition that emerged from the focus groups was: “A dynamic, psychosocial process which protects a group of individuals from the potential negative effect of stressors they collectively encounter. It comprises of processes whereby team members use their individual and collective resources to positively adapt when experiencing adversity.” Overall, this definition suggests that team resilience is an important capacity in sport since it enables groups to withstand stressors by the utilizing and optimizing of psychosocial factors at two different levels (i.e., individual and team). The emergence of "a dynamic process" within the definition, and the psychosocial resources identified by the four resilient characteristics, suggest that team resilience can be manifested and conceived differently in various circumstances. Although the findings share similarities with individual resilience research in defining resilience as a dynamic phenomenon (cf. Luthar et al., 2000), a distinct aspect of the definition presented in this study is the identification of "psychosocial” processes. This unique feature of team resilience appears to capture the interactions between cognitive, affective and relational factors, indicating that resilience at the group level is likely more than the sum of a collection of resilient individuals (cf. Horne \& Orr, 1998). Importantly, although some of the characteristics unearthed in this study have previously been identified within sport psychology as features of effective teams (see, for a review, Kleinert et al., 2012), the findings presented here offer a distinct and novel insight into their specific role within the context of positively adapting to stressors.

A key overarching message emerging from the findings is that the quality of relationships is critical for team resilience and this was evident across the four characteristics. For example, within the group structure characteristic, formal structures, group norms, and 
1 communication channels clearly influenced resilient teams through their impact on

2 relationship management. A possible explanation for how group structure facilitates

3 resilience can be drawn from the work of Weick (1993) who suggested that structural aspects,

4 such as shared interpretive schemes, role systems, rules, and procedures, enable groups to

5 organize themselves during a crisis. These aspects appear to allow team members to

6 coordinate their responses to stressors through agreed patterns of behavior and the subsequent

7 creation of collective sense making (see, e.g., Blatt, 2009). Quality relationships were also

8 critical within the resilient characteristic of social capital. Social capital has been defined as

9 "the goodwill available to individuals, groups, and organizations that lies in the structure and 10 content of their interpersonal relationships” (Lengnick-Hall \& Beck, 2005, p. 752).

11 Interestingly, this concept is similar to "psychosocial capital" identified by Wagstaff et al. (2012) as a factor regarded as important for optimal organizational functioning. Research has suggested that resilience at an organizational level is more likely to occur when rich social capital exists (Gittell et al., 2006). However, the higher-order theme of group identity, within the general dimension of social capital, appears to be a previously overlooked aspect of resilience in groups. The importance of this feature for resilient teams might be explained by the psychological concept of social identity (see Hogg \& Abrams, 1988). Specifically, it has been suggested that social identity takes over from individual identity through the formation of a relational schema about how one should behave in a group (Blatt, 2009). Consequently, team members may have stronger emotional ties and a lowered self-interest (Weick, 1993).

Regardless of the specific underlying mechanisms, what is clear is that the role of relationships is clearly vital for a team's capacity to respond positively to adversity. A second key overarching theme to originate from the results was that learning and team resilience are intertwined. The mastery-related characteristic unearthed in this study illustrates that resilient teams utilize a variety of mastery approaches. To illustrate, the 
1 higher-order themes of learning orientation and effective behavioral responses suggest that

2 resilient teams regard setbacks as a natural part of their development. Indeed, research has

3 shown that a task-involving climate leads to adaptive achievement patterns and positive

4 psychological responses (see, e.g., Seifriz, Duda, \& Chi, 1992). The mastery approaches

5 appear to characterize resilient teams by facilitating a broader outward focus during

6 adversity. In turn, this may increase a team's creativity and reduce threat rigidity in

7 potentially stressful situations (Blatt, 2009; Sutcliffe \& Vogus, 2003). Furthermore, the

8 notion of learning was critical within the resilient characteristic of collective efficacy. To

9 illustrate, the higher-order theme of past mastery experiences revealed that teams gained

10 collective belief and subsequent learning through experiences of success (cf. Goddard, Hoy,

11 \& Hoy, 2004). Notwithstanding this point, the findings of this study suggest that resilient teams are, somewhat paradoxically, also able to harness the collective experience of adversity. Specifically, the knowledge that a team has accumulated through encountering challenging situations may breed the belief that they can overcome future setbacks (cf. Sutcliffe \& Vogus, 2003). Hence, this study suggests that resilient teams regard the role of learning as being vital and this may operate through developing an improved learned resourcefulness and behavioral preparedness in adverse conditions (Lengnick-Hall et al., 2011).

When interpreting the findings of an investigation of this kind, it is important to recognize some of the strengths and limitations. In our view, the major strengths of the study relate to the characteristics of the sample and the context-specific nature of the generated definition. First, the make-up of the focus groups was a considerable strength of the study since they comprised Olympic medalists, world champions, international, and professional level athletes from a variety of team sports, all of whom had positively adapted to adversity at numerous points during their sporting career. Moreover, the sample size of 31 participants 
1 was relatively large compared to similar exploratory studies (e.g., Thomas, Lane, \&

2 Kingston, 2011). Secondly, by defining resilience in teams in elite sport, this study adhered to

3 Luthar et al.'s (2000) recommendation that resilience should be defined in relation to the

4 specific context in which it is manifested. Specifically, Luthar et al. argued that "in

5 describing findings, investigators must specify the particular spheres to which their data

6 apply ... thereby bringing greater precision to terminology commonly used in the literature”

7 (p. 548). Notwithstanding these strengths, a potential limitation of the study was the

8 exclusion of coaches within the focus groups who may have offered additional perspectives

9 of team resilience. However, it was deemed that focus groups with a mix of coaches and

10 athletes may have produced power imbalances and reduced natural interactions during the

11 discussions (cf. Morgan, 1997). Regarding the examination of data, although thematic analysis was appropriate for addressing the purposes of this study, this approach precluded the exploration of team member interactions which may have better revealed the discourses within the group context (Liamputtong, 2011).

This study has indicated that team resilience offers a fruitful avenue for future research. Due to the contextual and temporal nature of team resilience, future studies should aim to identify the processes that underpin the resilient characteristics (cf. Glantz \& Sloboda, 1999). Indeed, Luthar et al. (2000) stated that "such attention to underlying mechanisms is viewed as essential for advancing theory and research in the field, as well as for designing appropriate ... intervention strategies (p. 554)”. This type of research would be best realized through a longitudinal design to provide a greater understanding of how resources are used at different phases of a team's development. For example, it may be intuitively reasonable to assume that certain aspects of group structure might be particularly pertinent during the early phase of a team's formation. In addition, since teams consist of individuals with a collection 
1 personality traits in characterizing team resilience in elite sport (cf. Fletcher \& Sarkar, 2012).

2 Finally, future research could employ more creative qualitative methods to better understand

3 resilience in elite sport teams. To illustrate, autobiography analysis has been conducted using

4 analytical strategies, such as narrative analysis, to study psychological phenomena in sport

5 (see, e.g., Stewart et al., 2011) and this could be applied within a team resilience context to

6 elucidate how individuals within groups use stories to explain their sporting journeys.

From an applied perspective, the definition and characteristics of team resilience offer

8 a number of practical implications. The recognition of psychosocial processes within the

9 generated definition emphasizes the importance of teams having "relational reserves” (Gittell

et al., 2006, p. 302) to facilitate effective psychological responses in challenging circumstances (see also Blatt, 2009). Participants in this study also acknowledged that both individual and combined resources were required to demonstrate team resilience. Thus, sport psychologists should identify and monitor the desired resilient characteristics at two different levels (i.e., individual and team). The protective nature of team resilience suggests that practitioners should help teams to utilize and optimize the resilient characteristics as a buffer or shield specifically to enable teams to evaluate stressors as an opportunity for personal development and mastery.

The resilient characteristics identified in this study could provide sport psychologists with a framework to enhance team resilience. In turn, this could facilitate the design of teambased resilience interventions for athletes and coaches operating in elite sport. Indeed, educational programs in developing resilient characteristics should form a central part of resilience training (cf. Meredith et al., 2011; Reivich, Seligman, \& McBride, 2011). To illustrate, using the group structure components, practitioners could work with athletes and coaches to collectively develop a shared vision based on core values and a clear sense of purpose. The use of group debriefings and reflections of key incidents, underpinned by the 
1 identified core values, would promote a setting for shared constructive sense making amongst

2 team members about the lessons learnt after experiencing adversity. In relation to the mastery

3 approaches, coaches could employ simulation training exercises to enable teams to gain

4 experience of adversity, and to promote adaptability and behavioral preparedness. Based on

5 the social capital characteristic, positive relationships should be nurtured by ensuring

6 opportunities are created for informal interactions and social activities to build a sense of

7 camaraderie amongst team members and to reinforce a team identity via the use of images

8 (e.g., logos, mottos). Finally, to build collective efficacy, athletes and coaches might hold

9 small group meetings to reflect on the benefits of experiencing adversity and discovering

10 whether there are new strengths to be gained. They may also consider how to optimize the

11 impact of influential leaders to ensure that confidence is spread throughout the group during setbacks.

In conclusion, this study developed a definition of team resilience and identified the resilient characteristics of elite sport teams. Team resilience was defined as a dynamic, psychosocial process which protects a group of individuals from the potential negative effect of the stressors they collectively encounter. It comprises of processes whereby team members use their individual and collective resources to positively adapt when experiencing adversity. Four general dimensions emerged which characterized team resilience in elite sport: group structure, mastery approaches, social capital, and collective efficacy. These characteristics are a distinct set of resources peculiar to groups which, in line with Horne and Orr's (1998) reflections, suggest that individual resilience does not necessarily guarantee resilience at the group level. Indeed, the results reported here support Luthar’s (2006) claim that "resilience rests, fundamentally, on relationships” (p. 780) and show that this is particularly pertinent for teams seeking to excel at the highest levels of sport. 
References

Bennett, J. B., Aden, C. A., Broome, K., Mitchell, K., \& Rigdon, W. D. (2010). Team resilience for young restaurant workers: Research-to-practice adaptation and assessment. Journal of Occupational Health Psychology, 15, 223-236. doi:10.1037/a0019379

Blatt, R. (2009). Resilience in entrepreneurial teams: Developing the capacity to pull through. Frontiers of Entrepreneuship Research, 29, 1-16. Retrieved from http://digitalknowledge.babson.edu/fer

Braun, V., \& Clarke, V. (2006). Using thematic analysis in psychology. Qualitative Research in Psychology, 3, 77-101. doi:10.1191/1478088706qp0630a

Brodsky, A. E., Welsh, E., Carrillo, A., Talwar, G., Scheibler, J., \& Butler, T. (2011). Between synergy and conflict: Balancing the processes of organizational and individual resilience in an Afghan women's community. American Journal of Community Psychology, 47, 217-235. doi:10.1007/S10464-010-9399-5

Campbell-Sills, L., \& Stein, M. B. (2007). Psychometric analysis and refinement of the Connor-Davidson Resilience Scale (CD-RISC): Validation of a 10-item measure of resilience. Journal of Traumatic Stress, 20, 1019-1028. doi:10.1002/jts.20271

Chan, D. (1998). Functional relations among constructs in the same content domain at different levels of analysis: A typology of composition models. Journal of Applied Psychology, 83, 234-246. doi:10.1037/0021-9010.83.2.234

Connor, K. M., \& Davidson, J. R. T. (2003). Development of a new resilience scale: The Connor-Davidson Resilience Scale (CD-RISC). Depression and Anxiety, 18, 76-82. doi:10.1002/da.10113

Culver, D. M., Gilbert, W., \& Sparkes, A. (2012). Qualitative research in sport psychology journals: The next decade 2000-2009 and beyond. The Sport Psychologist, 26, 261- 
281. Retrieved from http://journals.humankinetics.com/tsp

Egeland, B., Carlson, E., \& Sroufe, L. A. (1993). Resilience as a process. Development and Psychopathology, 5, 517-528. doi:10.1017/S0954579400006131

Fletcher, D., \& Sarkar, M. (2012). A grounded theory of psychological resilience in Olympic champions. Psychology of Sport and Exercise, 13, 669-678. doi:10.1016/j.psychsport.2012.04.007

Fletcher, D., \& Sarkar, M. (in press). Psychological resilience: A review and critique of definitions, concepts and theory. European Psychologist.

Fletcher, D., \& Wagstaff, C. R. D. (2009). Organizational psychology in elite sport: Its emergence, application and future. Psychology of Sport and Exercise, 10, 427-434. doi:10.1016/j.psychsport.2009.03.009

Galli, N., \& Vealey, R. (2008). Bouncing back from adversity: Athletes' experiences of resilience. The Sport Psychologist, 22, 316-335. Retrieved from http://journals.humankinetics.com/tsp

Garmezy, N. (1991). Resilience and vulnerability to adverse developmental outcomes associated with poverty. American Behavioral Scientist, 34(4), 416-430.

Gittell, J. H., Cameron, K., Lim, S., \& Rivas, V. (2006). Relationships, layoffs, and organizational resilience: Airline industry responses to September 11. Journal of Applied Behavioral Science, 42, 300-329. doi:10.1177/0021886306286466

Glantz, M. D., \& Sloboda, Z. (1999). Analysis and reconceptualization of resilience. In M. D. Glantz, \& J. L. Johnson (Eds.), Resilience and development: Positive life adaptations (pp. 109-126). New York City, NY: Kluwer Academic.

Goddard, R. D., Hoy, W. K., \& Hoy, A. W. (2004). Collective efficacy beliefs: Theoretical developments, empirical evidence and future directions. Educational Researcher, 33, 3-13. Retrieved from http://edr.sagepub.com 
1 Gucciardi, D. F., Jackson, B., Coulter, T. J., \& Mallett, C. J. (2011). The Connor-Davidson Resilience Scale (CD-RISC): Dimensionality and age-related measurement invariance with Australian cricketers. Psychology of Sport \& Exercise, 12, 423-433. doi:10.1016/j.psychsport.2011.02.005

Guest, G., MacQueen, K. M., \& Namey, E. (2012). Applied thematic analysis. London, UK: Sage.

Hogg, M. A., \& Abrams, D. (1988). Social identifications: A social psychology of intergroup relations and group processes. London, UK: Routledge.

Holt, N. L., \& Dunn, J. G. H. (2004). Toward a grounded theory of the psychosocial competencies and environmental conditions associated with soccer success. Journal of Applied Sport Psychology, 16, 199-219. doi:10.1080/10413200490437949

Holt, N. L., \& Hogg, J. M. (2002). Perceptions of stress and coping during preparations for the 1999 Women’s Soccer World Cup Finals. The Sport Psychologist, 16, 251-271. Retrieved from http://journals.humankinetics.com/tsp

Horne, J. F. III, \& Orr, J. E. (1998, Winter). Assessing behaviors that create resilient organizations. Employment Relations Today, 29-39. Retrieved from http://onlinelibrary.wiley.com/journal/10.1002/(ISSN)1520-6459

King, N., \& Horrocks, C. (2010). Interviews in qualitative research. London, UK: Sage.

Kitzinger, J. (1994). The methodology of focus groups: The importance of interaction between research participants. Sociology of Health and Illness, 16(1), 103-121.

Kleinert, J., Ohlert, J., Carron, B., Eys, M., Feltz, D., Harwood, C., . . Sulprizio, M. (2012). Group dynamics in sports: An overview and recommendations on diagnostic and intervention. The Sport Psychologist, 26, 412-434. Retrieved from http://journals.humankinetics.com/tsp

Krueger, R. A., \& Casey, M. A. (2009). Focus groups: A practical guide for applied research 
1

( $4^{\text {th }}$ ed.). Thousand Oaks, CA: Sage.

Lengnick-Hall, C. A., \& Beck, T. E. (2005). Adaptive fit versus robust transformation: How organizations respond to environmental change. Journal of Management, 31, 738757. doi:10.1177/0149206305279367

Lengnick-Hall, C. A., Beck, T. E., \& Lengnick-Hall, M. L. (2011). Developing a capacity for organizational resilience through strategic human resource management. Human Resource Management Review, 21, 243-255. doi:10.1016/j.hrmr.2010.07.001

Liamputtong, P. (2011). Focus group methodology: Principles and practice. London, UK: Sage.

Luthar, S. S. (2006). Resilience in development: A synthesis of research across five decades. In D. Cicchetti \& D. J. Cohen (Eds.), Developmental psychopathology: Vol. 3. Risk, disorder, and adaptation (pp. 739-795). New York City, NY: Wiley.

Luthar, S. S., Cicchetti, D., \& Becker, B. (2000). The construct of resilience: A critical evaluation and guidelines for future work. Child Development, 71, 543-562. doi:10.1111/1467-8624.00164

Masten, A. S. (2001). Ordinary magic: Resilience processes in development. American Psychologist, 56, 227-238. doi:10.1037/0003-066X.56.3.227

Masten, A. S., \& O’Dougherty Wright, M. (2010). Resilience over the lifespan. In J. W. Reich, A. J. Zautra, \& J. Stuart-Hall (Eds.), Handbook of adult resilience (pp. 213237). New York City, NY: The Guildford Press.

Meredith, L. S., Sherbourne, C. D., Gaillot, S., Hansell, L., Ritschard, H. V., Parker, A. M., \& Wren, G. (2011). Promoting psychological resilience in the US military. Santa Monica, CA: Rand Corporation.

Morgan, D. (1997). Focus groups as qualitative research. London, UK: Sage.

Nicholls, A. R., Polman, R., Levy, A. R., Taylor, J., \& Cobley, S. (2007). Stressors, coping 

and coping effectiveness: Gender, type of sport, and skills differences. Journal of Sports Sciences, 25, 1521-1530. doi:10.1080/02640410701230479

Noblett, A. J., \& Gifford, S. M. (2002). The sources of stress experienced by professional Australian footballers. Journal of Applied Sport Psychology, 14, 1-13. doi:10.1080/10413200209339007

Norris, F. H., Stevens, S. P., Pfefferbaum, B., Wyche, K. F., \& Pfefferbaum, R. L. (2008). Community resilience as a metaphor, set of capacities, and strategy for disaster readiness. American Journal of Community Psychology, 41, 127-150. doi:10.1007/s10464-007-9156-6

QSR Nvivo (Version 9) [Computer software]. Melbourne, Australia: Qualitative Solutions \& Research International, Pty Ltd (QSR).

Reivich, K. J., Seligman, M. E. P., \& McBride, S. (2011). Master resilience training in the US army. American Psychologist, 66, 25-34. doi:10.1037/a0021897

Richardson, G. E. (2002). The metatheory of resilience and resiliency. Journal of Clinical Psychology, 58, 307-321. doi:10.1002/jclp.10020

Roulston, K. (2010a). Considering quality in qualitative interviewing. Qualitative Research, 10, 199-228. doi:10.1177/1468794109356739

Roulston, K. (2010b). Reflective interviewing: A guide to theory and practice. London, UK: Sage.

Seifriz, J., Duda, J. L., \& Chi, L. (1992). The relationship of perceived motivational climate to intrinsic motivation and beliefs about success in basketball. Journal of Sport and Exercise Psychology, 14, 375-391. Retrieved from http://journals.humankinetics.com/jsep

Silverman, D. (2006). Interpreting qualitative data: Methods for analyzing talk, text, and interaction (3rd ed.). London, UK: Sage. 
1 Sparkes, A. C., \& Smith, B. (2009). Judging the quality of qualitative inquiry: Criteriology and relativism in action. Psychology of Sport and Exercise, 10, 491-497. doi:10.1016/j.psychsport.2009.02.006

Stewart, C., Smith, B., \& Sparkes, A. C. (2011). Sporting autobiographies of illness and the role of metaphor. Sport in Society, 14, 581-597. doi:10.1080/17430437.2011.574358

Stewart, D. W., \& Shamdasani, P. N. (1990). Focus groups: Theory and research, Newbury Park, CA: Sage.

Stewart, D. W., Shamdasani, P. N., \& Rook, D. W. (2007). Focus groups: Theory and practice. Thousand Oaks, CA: Sage.

Sutcliffe, K. M., \& Vogus, T. J. (2003). Organizing for resilience. In K. S. Cameron, J. E. Dutton, \& R. E. Quinn (Eds.), Positive organizational scholarship: foundations of a new discipline (pp. 94-110). San Francisco, CA: Berrett-Koechler.

Thomas, O., Lane, A. \& Kingston, K. (2011). Defining and contextualizing robust sportconfidence. Journal of Applied Sport Psychology, 23, 189-208. doi:10.1080/10413200.2011.559519

Tracy, S. J. (2010). Qualitative quality: Eight “big tent” criteria for excellent qualitative research. Qualitative Inquiry, 16, 837-851. doi:10.1177/1077800410383121

Ungar, M. (2003). Qualitative contributions to resilience research. Qualitative Social Work, 2, 85-102. doi:10.1177/1473325003002001123

Wagstaff, C. R. D., Fletcher, D., \& Hanton, S. (2012). Positive organizational psychology in sport: An ethnography of organizational functioning in a national sport organization. Journal of Applied Sport Psychology, 24, 26-47. doi: 10.1080/10413200.2011.589423

Weick, K. E. (1993). The collapse of sensemaking in organizations: The Mann Gulch disaster. Administrative Science Quarterly, 38(4), 628-652.

Werner, E. E., \& Smith, R. S. (1992). Overcoming the odds: High risk children from birth to 

adulthood. New York City, NY: University Press.

2 West, B. J., Patera, J. L., \& Carsten, M. K. (2009). Team level positivity: Investigating positive psychological capacities and team level outcomes. Journal of Organizational Behavior, 30, 249-267. doi:10.1002/job.593

5

6

7

8

9

10

11

12

13

14 
3 Recruiting and selecting 'team players'

3 Shared leadership roles

3

Strategic competition planning and management

3 Centralized team structures

\section{Formal structure}

vision during adversity

4 Agreed behavioral principles in difficult times

5 Group norms and values

5 Group structure

3 Group accountability

4 Open and honest

4 Using frequent communication

5 Communication channels

2 Positive verbal communication

2 Using humor during setbacks

Figure 1. Resilient Characteristics of Elite Sport Teams: Group Structure. 


\begin{tabular}{|l|l|}
\hline 5 & $\begin{array}{l}\text { Focusing on learning and } \\
\text { improvement as a group }\end{array}$ \\
\hline
\end{tabular}

$3 \quad$ Resetting the team focus to alleviate pressure

\begin{tabular}{|l|l|}
\hline 3 & $\begin{array}{l}\text { Reinforcing positives from } \\
\text { poor performances }\end{array}$ \\
\hline
\end{tabular}

$3 \quad$ Keeping a broadened perspective

\section{5} Learning orientation

5 withstand stressors

$3 \quad$ Refusal to give up despite setbacks Digging in when facing challenges

3 Sustaining high effort levels in difficult moments

2 Not dwelling on setbacks

$4 \quad$ Adaptability

challenging situations

4 Managing change

$3 \quad$ Flexibility

Figure 2. Resilient Characteristics of Elite Sport Teams: Mastery approaches. 

Loyalty to each other during adversity

5 Group identity

$4 \quad$ Trust and respect in tough times

4 Friendship in times of need

5 Emotional support

\begin{tabular}{|l|l}
\hline & Tangible support
\end{tabular}

4 Esteem support

4 No blame culture when experiencing failure

\section{5 Perceived social support}

Selfless exchanges during challenging situations

2 Frequency of positive interactions

Figure 3: Resilient Characteristics of Elite Sport Teams: Social Capital. 
5 Gaining belief from past successes

4 Drawing on experience of adversity

3 Fighting spirit in challenging situations

3

Sticking to the task in difficult moments

\section{Past mastery experiences}

3 Commitment to the team

3

Working together during setbacks

3 Sustaining team morale

3 Others spreading belief after failure

3

Exhibiting a positive team attitude

3

Gaining feedback after disappointment

Figure 4. Resilient Characteristics of Elite Sport Teams: Collective Efficacy. 